\title{
Influencing mechanisms of lifestyle and dietary factors on chronic diseases among community residents: updated evidence in Shanghai, China
}

\author{
Yan Yang ${ }^{1}$, Hua Jin ${ }^{3,4}$, Peipei Zhang ${ }^{5}$, Mingwang Cheng ${ }^{1}$, Xiang Liu ${ }^{6}$, Zilong Cao ${ }^{2}$, \\ Xiang Gao ${ }^{2}$, Liang Zhou ${ }^{2}$, Yipeng Lv², Jiaoling Huang ${ }^{2}$, Ning Chen ${ }^{2}$, Zhaoxin Wang ${ }^{2, *}$, \\ Jianwei Shi ${ }^{2,3, *}$ and Wenya $\mathrm{Yu}^{2, *}$ \\ 'School of Economics and Management, Tongii University, Shanghai, People's Republic of China: ${ }^{2}$ School of Public \\ Health, Shanghai Jiao Tong University School of Medicine, Shanghai 200025, People's Republic of China: \\ ${ }^{3}$ Department of General Practice, Yangpu Hospital, Tongji University School of Medicine, Shanghai, People's Republic \\ of China: ${ }^{4}$ Shanghai General Practice and Community Health Development Research Center, Shanghai, People's \\ Republic of China: ${ }^{5}$ Anting Hospital, Jiading District, Shanghai, People's Republic of China: ${ }^{6}$ Department of \\ Respiratory Disease, The 903rd Hospital of PLA, Hangzhou, Zhejiang, People's Republic of China
}

Submitted 5 March 2021: Final revision received 31 August 2021: Accepted 17 0ctober 2021: First published online 29 0ctober 2021

\begin{abstract}
Objectives: This study aimed to determine the risk factors for chronic diseases and to identify the potential influencing mechanisms from the perspectives of lifestyle and dietary factors. The findings could provide updated and innovative evidence for the prevention and control of chronic diseases.

Design: A cross-sectional study.

Setting: Shanghai, China.

Participants: 1005 adults from Yangpu district of Shanghai participated in the study, and responded to questions on dietary habits, lifestyle and health status. Results: Residents suffering from chronic diseases accounted for about 34.99\% of the respondents. Logistic regression analysis showed that age, diet quality, amount of exercise and tea drinking were related to chronic diseases. Age $>60$ and overeating (Diet Balance Index total score $>0$ ) had negative additive interaction on the occurrence of chronic disease, while overexercise (Physical Activity Index $>17 \cdot 1$ ) and tea drinking had negative multiplicative interaction and negative additive interaction on the occurrence of chronic disease. Diet quality, physical activity and tea drinking were incomplete mediators of the relationship between types of medical insurance residents participating in and chronic diseases.

Conclusions: The residents in Yangpu District of Shanghai have a high prevalence of chronic diseases. Strengthening access of residents to health education and interventions to prevent chronic diseases and cultivating healthy eating and exercise habits of residents are crucial. The nutritional environment of the elderly population should be considered, and the reimbursement level of different types of medical insurance should be designed reasonably to improve the accessibility of medical and health services and reduce the risk of chronic diseases.
\end{abstract}

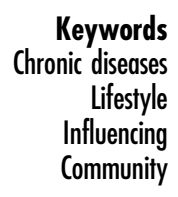

As societies develop, the spectrum of diseases and number of deaths in urban residents undergo dramatic changes, and chronic diseases have become an important public health issue threatening residents' health ${ }^{(1)}$.

Yan Yang, Hua Jin and Peipei Zhang contributed equally to this work and were co-first authors.
Chronic non-communicable diseases (NCD), including heart disease, stroke, cancer, diabetes and chronic lung disease, are collectively responsible for almost $70 \%$ of all deaths worldwide ${ }^{(2)}$. Furthermore, NCD are more severe in low-and-middle-income countries, accounting for almost three quarters of all NCD' deaths and $82 \%$ of the 16 million people who die prematurely or before reaching age 70 years in low-and-middle-income 
countries $^{(3)}$. In China, due to the increased prevalence, the total number of deaths from NCD have increased, with $17 \%$ of people dying prematurely from any of cardiovascular diseases, cancers, diabetes or chronic respiratory diseases ${ }^{(4)}$. The high morbidity, disability and mortality from NCD bring about huge sufferings to the patients and their families, with very heavy medical cost. Therefore, the prevention and control of NCD have become an important public health issue ${ }^{(5)}$.

Previous studies in low-and-middle-income countries revealed the impact of demographical and sociological characteristics and lifestyle and environmental exposure on chronic diseases ${ }^{(6-8)}$. A study from rural India showed age, gender, socioeconomic status and geographical location of residence as predictors of chronic disease prevalence $^{(9)}$. A study of six low-and-middle-income countries and upper-middle income countries, including South Africa, Mexico, India, Ghana, Russia and China, revealed that daily smoking, frequent alcohol abuse, low levels of physical activity, insufficient intake of vegetables and fruits, high risk waist-to-hip ratio, obesity and high blood pressure are the main risk factors for chronic diseases ${ }^{(10)}$. Consistent findings reported in Chinese studies revealed that in Ningxia, a remote province in northern China, gender, age, ethnicity, education, marital status, occupation and source of drinking water are the main influencing factors of chronic diseases among residents ${ }^{(11)}$. In another northeastern cityChangchun-survey, age, occupation, physical activity and income are the top five risk factors for chronic diseases $^{(12)}$. With increasing urbanisation and aging, changes in the socio-economic levels and lifestyles of residents have caused great changes in the spectrum, morbidity and mortality of chronic diseases ${ }^{(13,14)}$. However, few of these previous studies have examined the comprehensive impact mechanisms of medical insurance, modern lifestyle, diet quality and other factors on chronic diseases.

Therefore, this study was aimed to determine the prevalence of chronic diseases among the population in the surveyed area, explore their influencing factors and identify the underlying mechanisms among Shanghai, a highly urbanised city with well-developed social services. The results of this study are expected to provide updated and innovative evidence for the prevention and control of chronic diseases, especially in urban cities in developing countries.

\section{Methods}

\section{Data sources}

The data we used were from the survey of chronic diseases by Shanghai Center for Disease Control and Prevention in 2016. This survey included 1005 residents from 240 households in all 12 community streets in Yangpu District, Shanghai, and 20 households were randomly selected from each street. The survey was conducted at the household level, and personal questionnaires were used to obtain data from family members. The respondents were community residents who had lived in the targeted district for at least 6 months preceding the survey. The questionnaire was completed by professional investigators, and the information obtained was recorded in the information system.

The survey included four sections: (1) basic family information, including the number of family members, financial status, family diet and fuel usage; (2) basic personal information, including age, sex, education level, marital status, occupation, medical insurance participation and registered permanent residence; (3) personal dietary habits and lifestyles, including food intake, smoking, second-hand smoking, alcohol drinking, salt intake (self-assessment), tea drinking and amount of exercise and (4) personal health status, including weight status (self-assessment), height (actual measurement), weight (actual measurement), blood pressure and presence of chronic diseases. The questionnaire also included related information such as family history of chronic diseases. A total of 1005 completed questionnaires were collected, including 22 questionnaires with inconsistent or illogical responses. Ultimately, 983 valid questionnaires were retained, and the effective rate was $97 \cdot 81 \%$.

\section{Measurement}

\section{Dietary quality}

Most of the existing researches mainly included single nutrients or food composition indicators to measure the dietary structure or quality of residents; these can only reflect a certain aspect of the diet and hardly explain the complexity of the diet ${ }^{(15)}$. To evaluate the overall dietary quality and diet structure, this study comprehensively considered the problem of insufficient and excessive dietary intake and quantified the degree based on Chinese Diet Balance index ${ }^{(16)}$, which can better evaluate the dietary quality of Chinese adults.

Diet Balance Index_16 (DBI_16) is composed of eight food group level indicators, including cereal, fruits and vegetables, dairy, soybean, animal food (red meat and products, poultry and game, aquatic products, eggs), pure heat food (cooking oil and alcoholic beverage), condiments (added sugar and salt), diet variety and water. If the water quantity data is missing, such was excluded from the analysis ${ }^{(16)}$. The individual indicator in each group were set according to eleven energy levels, and the specific values were based on the revised standards of China's Dietary index ${ }^{(17)}$. The DBI score is used to calculate the high bound score, low bound score, total score (TS) and diet quality distance from the eight indicators. High bound score was calculated by adding the positive scores of all indicators to indicate the degree of dietary overconsumption; low bound score, the absolute value of the sum of the negative points of all indicators, reflects the degree of insufficient 
dietary intake; TS, the sum of the scores of all indicators, reflects the average level of the overall dietary quality; while diet quality distance, the sum of the absolute values of each indicator, comprehensively reflects the problems with a particular diet.

Using the DBI_16 evaluation method, the average daily food intake of each group was first calculated, and the energy intake was calculated according to the food composition table 17. The DBI_16 index score of each person was then calculated according to the DBI_16 scoring method to derive the DBI_TS, Diet Balance Index high bound score and Diet Balance Index low bound score. To better reflect the average level of the dietary quality, DBI_TS was selected as the proxy variable of dietary quality in this study. Negative DBI_TS implied undereating by the people on the average; positive DBI_TS implied overeating on the average; while zero DBI_TS does not necessarily imply a balanced diet, but may mean that the degree of overeating and undereating of different kinds of food is equal; hence, they cancel out. DBI_TS ranges from -72 to 44 . According to the quartile, the Dietary quality was classified into four categories: dietary under intake (DBI_TS $\leq-14$ ), mild dietary under intake $(-14<$ DBI_TS $\leq 0)$, mild overeating $(0<$ DBI_TS $\leq 8)$ and overeating (DBI_TS $>8)$.

\section{Amount of exercise}

Individual physiological load of exercise was measured according to the international general Physical Activity Index (PAI) ${ }^{(18)}$. Housework, working activities (reading, writing, reporting, etc.), outdoor activities (running, swimming, ball games, etc.) and other different types of exercise were assigned $0 \cdot 85-9$ points per hour and multiplied by the corresponding time to calculate the PAI. According to the quartile, the PAI was classified into four categories: appropriate amount of physical activity (PAI $<12 \cdot 8$ ), mild overexercise $\quad(12.8<\mathrm{PAI} \leq 17 \cdot 1)$, moderate overexercise $(17 \cdot 1<\mathrm{PAI} \leq 22.5)$ and severe overexercise (PAI > 22.5).

\section{Assessment of chronic disease status}

Participants were asked to report only NCD that were once diagnosed by medical staff. Hypertension, diabetes, dyslipidemia or hyperlipidemia, chronic kidney disease, cardiovascular and cerebrovascular events were provided as examples. No chronic disease was recorded as ' 0 ' and having one or more chronic diseases were recorded as ' 1 '.

\section{Statistical analysis}

The data collected were recorded in Information Collection Management Platform by investigators, analysed using IBM SPSS version 23.0; Stata version 13.0 and $\mathrm{R}$ version 2.8.1, and reported in frequency distribution tables. Chi-square test, logistic regression analysis and mediating effect test were performed. Chi-square tests and non-conditional logistic regression analysis were used to identify factors associated with chronic disease. Addition and multiplication interaction models were used to analyse the interaction of different risk factors on chronic disease. The synergy index (S), relative excess risk due to interaction and attributable proportion due to interaction were calculated with reference to the interaction calculation table compiled by Andersson et al., and determined whether there is additive interaction $^{(19,20)}$. All tests were bilateral, and $P<0.05$ was considered statistically significant.

The mediating effect model was used to further test whether medical insurance influenced chronic diseases through dietary quality, exercise and tea drinking variables. Taking dietary quality (DBI_TS) as an example to explore the influence mechanism of residents' participation in medical insurance on chronic disease. DBI_TS was the mediation variable (reported as a continuous variable), the independent variable was types of health insurance that residents participate in (reported as a categorical variable), while the dependent variable, having or not having chronic disease, was a dichotomous variable. The specific models are as follows:

$$
\begin{gathered}
\text { TS }_{i}=\alpha+\beta_{1} \text { Medical insurance }_{i}+\beta_{2} \text { Control }_{i}+\zeta_{i} \\
\text { Chronic disease }_{i}=\alpha+\gamma_{1} \text { Medical insurance }_{i}+\gamma_{2} \text { Control }_{i}+\zeta_{i}
\end{gathered}
$$

In the mediation analysis, where the mediating variable or dependent variable was a categorical variable, the usual linear regression analysis was replaced by the logistic regression analysis ${ }^{(21-23)}$. Since the dependent variable was a categorical variable, equations (2) and (3) for logistic regression analysis were adopted. Since the mediating variable was a continuous variable, the linear regression analysis in equation (1) was used ${ }^{(24-26)}$. The same was true for the analysis that medical insurance affected the risk of chronic disease by influencing the amount of exercise or tea consumption of residents.

The RMediation software package in $\mathrm{R}$ was used to calculate the $\mathrm{CI}$ for the mediation variable statistics. The significance level was set at $P<0.05$ for all the tests. Since the family history of chronic diseases was a perfect predictor of chronic diseases, it was automatically omitted from the multiple logistic regression model. Considering that members from the same family are more similar in diet and other living habits, individuals with a family history of chronic diseases are more likely to experience chronic diseases. Therefore, family history of chronic diseases was not discussed in the follow-up analysis.

\section{Data quality}

Myer's blended index is a method used to estimate the quality of survey data based on the age distribution of the participants. The index score ranges from 0 to 99 and cannot be greater than 60, otherwise, that indicates a serious quality problem with the survey demographic data. In general, 
Table 1 Socio-demographic characteristics of the respondents ( $n$ 983)

\begin{tabular}{|c|c|c|c|}
\hline \multirow[b]{2}{*}{ Variable } & \multirow[b]{2}{*}{ Group } & \multicolumn{2}{|c|}{ Total $(n 983)$} \\
\hline & & $n$ & $\%$ \\
\hline \multicolumn{4}{|l|}{ Socio-demographic characteristics } \\
\hline \multirow[t]{5}{*}{ Age (years) } & $18-30$ & 27 & $2 \cdot 75$ \\
\hline & $31-45$ & 87 & 8.85 \\
\hline & $46-60$ & 294 & 29.91 \\
\hline & $61-75$ & 459 & 46.69 \\
\hline & $>75$ & 116 & 11.80 \\
\hline \multirow[t]{2}{*}{ Sex } & Male & 408 & 41.51 \\
\hline & Female & 575 & 58.49 \\
\hline \multirow[t]{4}{*}{ Education } & Primary school or below & 85 & 8.65 \\
\hline & Junior high school & 334 & 33.98 \\
\hline & Senior high school & 406 & 41.30 \\
\hline & Bachelor's degree or above & 158 & $16 \cdot 07$ \\
\hline \multirow[t]{3}{*}{ Marital status } & Unmarried & 28 & 2.85 \\
\hline & Married & 906 & $92 \cdot 17$ \\
\hline & Widowed or divorced & 49 & 4.98 \\
\hline \multirow[t]{9}{*}{ Occupation } & Operators of production and transport equipment & 21 & $2 \cdot 14$ \\
\hline & Personnel of business and services & 24 & 2.44 \\
\hline & Personnel of government, political party, enterprise & 7 & 0.71 \\
\hline & Clerk and related personnel & 38 & 3.87 \\
\hline & Professional technical personnel & 61 & $6 \cdot 21$ \\
\hline & Other workers & 44 & 4.48 \\
\hline & Student or unemployed & 13 & 1.32 \\
\hline & Household & 7 & 0.71 \\
\hline & Retirees & 768 & $78 \cdot 13$ \\
\hline \multirow[t]{5}{*}{ Monthly family income $\left(\mathrm{CNY}^{\star}\right)$} & $<5000$ & 162 & 16.48 \\
\hline & $5001-8000$ & 217 & 22.08 \\
\hline & $8001-11000$ & 523 & 53.20 \\
\hline & $11001-14000$ & 27 & 2.75 \\
\hline & $>14000$ & 54 & 5.49 \\
\hline \multirow[t]{4}{*}{ Medical insurance $\dagger$} & Nonparticipant & 23 & $2 \cdot 34$ \\
\hline & Urban and Rural Residents' Medical Insurance (URRMI) & 227 & 23.09 \\
\hline & Urban Employees Basic Medical Insurance (UEBMI) (not retired) & 192 & 19.53 \\
\hline & UEBMI (retired) & 541 & 55.04 \\
\hline \multirow[t]{2}{*}{ Registered residence in Shanghai } & Yes & 965 & $98 \cdot 17$ \\
\hline & No & 18 & 1.83 \\
\hline \multicolumn{4}{|l|}{ Health status and family history } \\
\hline \multirow[t]{4}{*}{ Weight status (self-assessment) } & Thin & 65 & $6 \cdot 61$ \\
\hline & Normal & 735 & 74.77 \\
\hline & Overweight & 167 & 16.99 \\
\hline & Fat & 16 & 1.63 \\
\hline BMI‡ & Thin $(<18.5)$ & 19 & 1.95 \\
\hline & Normal (18.5-23.9) & 453 & 46.41 \\
\hline & Overweight (24-27.9) & 386 & 39.55 \\
\hline & Obesity $(\geq 28)$ & 118 & 12.09 \\
\hline Family history of chronic diseases & Yes & 831 & 84.54 \\
\hline & No & 152 & 15.46 \\
\hline Individual chronic diseases & Yes & 344 & 34.99 \\
\hline & No & 639 & $65 \cdot 01$ \\
\hline Dietary and living behavior (last 12 & & & \\
\hline Smoking & Never smoke & 859 & 87.39 \\
\hline & Used to smoke & 45 & 4.58 \\
\hline & Smoke (not everyday) & 12 & 1.22 \\
\hline & Smoking everyday & 67 & $6 \cdot 82$ \\
\hline Second-hand smoking & Never & 640 & $65 \cdot 11$ \\
\hline & $1-2 \mathrm{~d} /$ week & 134 & 13.63 \\
\hline & 3-4 d/week & 38 & 3.87 \\
\hline & $5-6 \mathrm{~d} /$ week & 30 & 3.05 \\
\hline & Everyday & 141 & $14 \cdot 34$ \\
\hline Alcohol drinking & Never & 800 & 81.38 \\
\hline & Less than $1 \mathrm{~d} /$ month & 66 & $6 \cdot 71$ \\
\hline & $1-3 \mathrm{~d} /$ month & 43 & 4.37 \\
\hline & $1-2 \mathrm{~d} /$ week & 32 & 3.26 \\
\hline & 3-4 d/week & 9 & 0.92 \\
\hline & $5-6 \mathrm{~d} /$ week & 2 & 0.20 \\
\hline & Everyday & 31 & $3 \cdot 15$ \\
\hline
\end{tabular}


Table 1 Continued

\begin{tabular}{|c|c|c|c|}
\hline \multirow[b]{2}{*}{ Variable } & \multirow[b]{2}{*}{ Group } & \multicolumn{2}{|c|}{ Total $(n 983)$} \\
\hline & & $n$ & $\%$ \\
\hline \multirow[t]{3}{*}{ Salt intake (self-assessment) } & Less & 224 & 22.79 \\
\hline & Moderate & 679 & 69.07 \\
\hline & More & 80 & 8.14 \\
\hline \multirow[t]{5}{*}{ Tea drinking } & Never or hardly & 658 & 66.94 \\
\hline & Only on special occasion & 53 & $5 \cdot 39$ \\
\hline & Only for certain months & 11 & $1 \cdot 12$ \\
\hline & Every month (less than once a week) & 17 & 1.73 \\
\hline & Every week & 244 & $24 \cdot 82$ \\
\hline \multirow{4}{*}{ Diet quality (DBI_TS)§ } & Dietary under intake $(<-14)$ & 228 & 23.70 \\
\hline & Mild dietary under intake $(-14-0)$ & 261 & $27 \cdot 13$ \\
\hline & Mild overeating $(0-8)$ & 242 & $25 \cdot 16$ \\
\hline & Overeating (> 8) & 231 & 24.01 \\
\hline \multirow[t]{4}{*}{ Physical activity index§ } & Appropriate amount of physical activity $(<12 \cdot 8)$ & 255 & 25.94 \\
\hline & Mild overexercise $(12.9-17.1)$ & 240 & 24.42 \\
\hline & Moderate overexercise $(17.2-22.5)$ & 252 & $25 \cdot 64$ \\
\hline & Severe overexercise $(>22.5)$ & 236 & $24 \cdot 01$ \\
\hline
\end{tabular}

${ }^{*}$ CNY: Chinese Yuan (currency unit). The average exchange rate between USD and the CNY in 2016 was 6.6423.

†Since 2016, China has started the merger of New Rural Cooperative Medical Insurance System and Urban Residents Basic Medical Insurance, collectively referred to as URRMI. Due to the availability of data and the convenience of interpretation, the two were combined in this study. In addition, since the reimbursement ratio of urban employees after retirement is significantly higher than that before retirement, the UEBMI can be divided into two groups (not retire $v$. retired) according to China's statutory retirement age (males retire at the age of 60 and females retire at the age of 50 ).

$\ddagger \mathrm{BMI}$ was calculated by the actually measured height and actually measured weight, and was divided into six categories according to guidelines for the prevention and control of overweight and obesity in adults in China.

$\S$ Classified by quartile.

errors while completing the question on age may occur due to 'number preference' and 'age heaping', and several participants tend to report the last digit of their ages as 0 or $5^{(27)}$. In this study, the Myer's blended index of the survey data was 4.49 , indicating that there was no data heaping; thus, confirming the overall validity of the data collected.

\section{Results}

\section{Socio-economic and demographic characteristics}

As shown in Table 1, most respondents were aged 61-75 years (46.69\%), women (58.49\%), graduated from senior high school (41.30\%), married (92.17\%), retired (78.13\%), enjoyed Urban Employees Basic Medical Insurance and retired (55.04\%), and were registered Shanghai residents (98.17\%). In terms of the health status, $77.74 \%$ of the respondents evaluated themselves as having normal weight, while the BMI showed that $46.41 \%$ of the respondents actually had normal BMI level, and $51.64 \%$ of the respondents were above normal BMI level. Of the 983 respondents, $34.99 \%$ had chronic diseases and $84.54 \%$ had a family history of chronic diseases.

\section{Univariate analysis of chronic disease risk factors}

The univariate analysis results showed that age, marital status, occupation, monthly family income, medical insurance, weight status (self-assessment), family history of chronic diseases, smoking, second-hand smoking, alcohol drinking, salt intake(self-assessment), tea drinking, diet quality (DBI_TS) and PAI were associated individually with chronic diseases (all $P<0.05$; Table 2).

\section{Logistic regression analysis of chronic disease risk factors}

The results of the logistic regression analysis, including significant variables in the chi-square test are shown in Table 3. Age, tea drinking, diet quality (DBI_TS) and PAI were significant influencing factors of chronic diseases. Among these factors, a higher prevalence of chronic disease was related to older age, drinking tea more often, more unbalanced diet and more excessive exercise.

Specifically, logistic regression analysis showed that, in the case of adjusting relevant variables, the risk of chronic disease of residents aged 46-60, 61-75 and $>75$ were $6 \cdot 88$ times (95\% CI: 1.47, 32.21), $8 \cdot 54$ times (95\% CI: 1·80, 40.56) and $10 \cdot 21$ times (95\% CI: 2.02, 51.52), compared with residents aged 18-30. Compared with those never or hardly drank tea, the risk of chronic disease was 1.84 times (95\% CI: 1.30, 2.61) for those who drank tea weekly. Compared with the Dietary under intake (DBI_TS $\leq-14$ ), the risk of chronic disease in the population with mild overeating $(0<$ DBI_TS $\leq 8)$ or overeating (DBI_TS $>8)$ were 2.04 times (95\% CI: 1.32, 3.16) and 1.76 times (95\% CI: $1 \cdot 13,2 \cdot 74)$. Relative to residents with appropriate amount of physical activity (PAI $<12 \cdot 8)$, the risk of chronic disease in mild overexercise $(12 \cdot 8<\mathrm{PAI} \leq 17 \cdot 1)$, moderate overexercise $(17 \cdot 1<\mathrm{PAI} \leq 22.5)$ and severe overexercise $(\mathrm{PAI}>22 \cdot 5)$ group were 2.34 times (95\% CI: $1.47,3.74)$, 4.13 times (95\% CI: 2.61, 6.53) and 4.42 times (95\% CI: $2 \cdot 75,7 \cdot 11$ ), respectively (Table 3 ). 
Table 2 Socio-demographic characteristics, health status, lifestyle and chronic diseases ( $n$ 983)

\begin{tabular}{|c|c|c|c|c|c|c|c|}
\hline \multirow[b]{2}{*}{ Variable } & \multirow[b]{2}{*}{$\chi^{2} /$ T value } & \multirow[b]{2}{*}{$P$ value } & \multirow[b]{2}{*}{ Number } & \multicolumn{2}{|c|}{$\begin{array}{l}\text { Without chronic } \\
\text { disease }\end{array}$} & \multicolumn{2}{|c|}{$\begin{array}{c}\text { Having chronic } \\
\text { disease }\end{array}$} \\
\hline & & & & $n$ & $\%$ & $n$ & $\%$ \\
\hline \multicolumn{8}{|l|}{ Socio-demographic characteristics } \\
\hline Age (years) & 29.623 & $<0.001$ & & & & & \\
\hline $18-30$ & & & 27 & 25 & $2.54 \%$ & 2 & $0.20 \%$ \\
\hline $31-45$ & & & 87 & 72 & $7.32 \%$ & 15 & $1.53 \%$ \\
\hline $46-60$ & & & 294 & 191 & $19.43 \%$ & 103 & $10.48 \%$ \\
\hline $61-75$ & & & 459 & 290 & $19.50 \%$ & 169 & $17 \cdot 19 \%$ \\
\hline$>75$ & & & 116 & 61 & $6 \cdot 21 \%$ & 55 & $5.60 \%$ \\
\hline & -4.96 & $<0.001$ & 983 & $59 \cdot 37$ & 13.45 & $63 \cdot 61$ & $10 \cdot 76$ \\
\hline Sex & 0.19 & 0.66 & & & & & \\
\hline Male & & & 408 & 262 & $26.65 \%$ & 146 & $14.85 \%$ \\
\hline Female & & & 575 & 377 & $38.35 \%$ & 198 & $20.14 \%$ \\
\hline Education & $5 \cdot 764$ & 0.12 & & & & & \\
\hline Primary school or below & & & 85 & 63 & $6.41 \%$ & 22 & $2 \cdot 24 \%$ \\
\hline Junior high school & & & 334 & 209 & $21.26 \%$ & 125 & $12 \cdot 72 \%$ \\
\hline Senior high school & & & 406 & 271 & $27.57 \%$ & 135 & $13.73 \%$ \\
\hline Bachelor's degree or above & & & 158 & 96 & $9.77 \%$ & 62 & $6.31 \%$ \\
\hline Marital status & $12 \cdot 79$ & 0.002 & & & & & \\
\hline Unmarried & & & 28 & 25 & $2.54 \%$ & 3 & $0.31 \%$ \\
\hline Married & & & 906 & 590 & $60.02 \%$ & 316 & $32.15 \%$ \\
\hline Widowed or divorced & & & 49 & 24 & $2.44 \%$ & 25 & $2.54 \%$ \\
\hline Occupation & 33.37 & $<0.001$ & & & & & \\
\hline Operators of production and transport equipment & & & 21 & 10 & $1.02 \%$ & 11 & $1.12 \%$ \\
\hline Personnel of business and services & & & 24 & 20 & $2.03 \%$ & 4 & $0.41 \%$ \\
\hline Personnel of government, political party, enterprise & & & 7 & 4 & $0.41 \%$ & 3 & $0.31 \%$ \\
\hline Clerk and related personnel & & & 38 & 33 & $3.36 \%$ & 5 & $0.51 \%$ \\
\hline Professional technical personnel & & & 61 & 48 & $4.88 \%$ & 13 & 1.32 \\
\hline Other workers & & & 44 & 27 & $2.75 \%$ & 17 & $1.73 \%$ \\
\hline Student or unemployed & & & 13 & 13 & $1.32 \%$ & 0 & $0.00 \%$ \\
\hline Household & & & 7 & 7 & $0.71 \%$ & 0 & $0.00 \%$ \\
\hline Retirees & & & 768 & 477 & $48.52 \%$ & 291 & $29.60 \%$ \\
\hline Monthly family income $\left(\mathrm{CNY}^{\star}\right)$ & $22 \cdot 54$ & $<0.001$ & & & & & \\
\hline$<5000$ & & & 162 & 98 & $9.97 \%$ & 64 & $6.51 \%$ \\
\hline $5001-8000$ & & & 217 & 116 & $11.80 \%$ & 101 & $10.27 \%$ \\
\hline $8001-11000$ & & & 523 & 367 & $37.33 \%$ & 156 & $15 \cdot 87 \%$ \\
\hline $11001-14000$ & & & 27 & 21 & $2.14 \%$ & 6 & $0.61 \%$ \\
\hline$>14000$ & & & 54 & 37 & $3.76 \%$ & 17 & $1.73 \%$ \\
\hline Ln (Monthly family income) & $3 \cdot 26$ & 0.001 & & 9.04 & 0.42 & 8.94 & 0.48 \\
\hline Medical insurance $\dagger$ & $30 \cdot 723$ & $<0.001$ & & & & & \\
\hline Nonparticipant & & & 23 & 14 & $1.42 \%$ & 9 & $0.92 \%$ \\
\hline Urban and Rural Residents' Medical Insurance (URRMI) & & & 227 & 114 & $11.60 \%$ & 113 & $11.50 \%$ \\
\hline Urban Employees Basic Medical Insurance (UEBMI) (not retired) & & & 192 & 145 & $14.75 \%$ & 47 & $4.78 \%$ \\
\hline UEBMI (retired) & & & 541 & 366 & $37.23 \%$ & 175 & $17 \cdot 80 \%$ \\
\hline Registered residence in Shanghai & 0.42 & 0.52 & & & & & \\
\hline Yes & & & 965 & 626 & $63.68 \%$ & 339 & $34.49 \%$ \\
\hline No & & & 18 & 13 & $1.32 \%$ & 5 & $0.51 \%$ \\
\hline Health status and family history & & & & & & & \\
\hline Weight status (self-assessment) & $67 \cdot 808$ & $<0.001$ & & & & & \\
\hline Thin & & & 65 & 30 & $3.05 \%$ & 35 & $3.56 \%$ \\
\hline Normal & & & 735 & 531 & $54.02 \%$ & 204 & $20.75 \%$ \\
\hline Overweight & & & 167 & 70 & $7 \cdot 12 \%$ & 97 & $9.87 \%$ \\
\hline Fat & & & 16 & 8 & $0.81 \%$ & 8 & $0.81 \%$ \\
\hline BMI‡ & 1.07 & 0.79 & & & & & \\
\hline Thin $(<18.5)$ & & & 19 & 13 & $1.32 \%$ & 6 & $0.61 \%$ \\
\hline Normal (18.5-23.9) & & & 453 & 300 & $30.52 \%$ & 153 & $15.56 \%$ \\
\hline Overweight (24-27.9) & & & 386 & 247 & $25 \cdot 13 \%$ & 139 & $14 \cdot 14 \%$ \\
\hline Obesity $(\geq 28)$ & & & 118 & 73 & $7.43 \%$ & 45 & $4.58 \%$ \\
\hline & -1.09 & 0.28 & & $24 \cdot 21$ & $3 \cdot 32$ & $24 \cdot 45$ & $3 \cdot 31$ \\
\hline Family history of chronic diseases & 333.99 & $<0.001$ & & & & & \\
\hline Yes & & & 152 & 0 & $0.00 \%$ & 152 & $15.46 \%$ \\
\hline No & & & 831 & 639 & $65.01 \%$ & 192 & $19.53 \%$ \\
\hline Dietary and living behavior (last 12 months) & & & & & & & \\
\hline Smoking & 9.44 & 0.02 & & & & & \\
\hline Never smoke & & & 859 & 573 & $58.29 \%$ & 286 & $29.09 \%$ \\
\hline Used to smoke & & & 45 & 22 & $2.24 \%$ & 23 & $2.34 \%$ \\
\hline Smoke (not everyday) & & & 12 & 6 & $0.61 \%$ & 6 & $0.61 \%$ \\
\hline Smoking every day & & & 67 & 38 & $3.87 \%$ & 29 & $2.95 \%$ \\
\hline
\end{tabular}


Table 2 Continued

\begin{tabular}{|c|c|c|c|c|c|c|c|}
\hline \multirow[b]{2}{*}{ Variable } & \multirow[b]{2}{*}{$\chi^{2} / \mathrm{T}$ value } & \multirow[b]{2}{*}{$P$ value } & \multirow[b]{2}{*}{ Number } & \multicolumn{2}{|c|}{$\begin{array}{l}\text { Without chronic } \\
\text { disease }\end{array}$} & \multicolumn{2}{|c|}{$\begin{array}{l}\text { Having chronic } \\
\text { disease }\end{array}$} \\
\hline & & & & $n$ & $\%$ & $n$ & $\%$ \\
\hline Second-hand smoke & 22.97 & $<0.001$ & & & & & \\
\hline Never & & & 640 & 437 & $44.46 \%$ & 203 & $20.65 \%$ \\
\hline $1-2 \mathrm{~d} /$ week & & & 134 & 68 & $6.92 \%$ & 66 & $6.71 \%$ \\
\hline 3-4 d/week & & & 38 & 31 & $3.15 \%$ & 7 & $0.71 \%$ \\
\hline $5-6 \mathrm{~d} /$ week & & & 30 & 15 & $1.53 \%$ & 15 & $1.53 \%$ \\
\hline Everyday & & & 141 & 88 & $8.95 \%$ & 53 & $5.39 \%$ \\
\hline Alcohol drinking & 49.62 & $<0.001$ & & & & & \\
\hline Never & & & 800 & 557 & $56.66 \%$ & 243 & $24.72 \%$ \\
\hline Less than $1 \mathrm{~d} /$ month & & & 66 & 25 & $2.54 \%$ & 41 & $4.17 \%$ \\
\hline $1-3 \mathrm{~d} /$ month & & & 43 & 19 & $1.93 \%$ & 24 & $2.44 \%$ \\
\hline $1-2 \mathrm{~d} /$ week & & & 32 & 14 & $1.42 \%$ & 18 & $1.83 \%$ \\
\hline 3-4 d/week & & & 9 & 8 & $0.81 \%$ & 1 & $0.10 \%$ \\
\hline 5-6 d/week & & & 2 & 1 & $0.10 \%$ & 1 & $0.10 \%$ \\
\hline Everyday & & & 31 & 15 & $1.53 \%$ & 16 & $1.63 \%$ \\
\hline Salt intake (self-assessment) & $22 \cdot 04$ & $<0.001$ & & & & & \\
\hline Less & & & 224 & 140 & $14 \cdot 24 \%$ & 84 & $8.55 \%$ \\
\hline Moderate & & & 679 & 465 & $47 \cdot 30 \%$ & 214 & $21.77 \%$ \\
\hline More & & & 80 & 34 & $3.46 \%$ & 46 & $4.66 \%$ \\
\hline Tea drinking & 43.89 & $<0.001$ & & & & & \\
\hline Never or hardly & & & 658 & 474 & $48 \cdot 22 \%$ & 184 & $18 \cdot 72 \%$ \\
\hline Only on special occasion & & & 53 & 27 & $2.75 \%$ & 26 & $2.64 \%$ \\
\hline Only for certain months & & & 11 & 5 & $0.51 \%$ & 6 & $0.61 \%$ \\
\hline Every month (less than once a week) & & & 17 & 10 & $1.02 \%$ & 7 & $0.71 \%$ \\
\hline Every week & & & 244 & 123 & $12.51 \%$ & 121 & $12 \cdot 31 \%$ \\
\hline Diet quality (DBI_TS)§ & $22 \cdot 25$ & $<0.001$ & & & & & \\
\hline Dietary under intake $(<-14)$ & & & 228 & 177 & $18.40 \%$ & 51 & $5.30 \%$ \\
\hline Mild dietary under intake $(-14-0)$ & & & 261 & 173 & $17.98 \%$ & 88 & $9 \cdot 15 \%$ \\
\hline Mild overeating $(0-8)$ & & & 242 & 139 & $14.45 \%$ & 103 & $10 \cdot 71 \%$ \\
\hline Overeating $(>8)$ & & & 231 & 143 & $14.86 \%$ & 88 & $9 \cdot 15 \%$ \\
\hline & $-5 \cdot 22$ & $<0.001$ & & -7.36 & 19.02 & -1.12 & 14.53 \\
\hline Physical activity index§ & $73 \cdot 38$ & $<0.001$ & & & & & \\
\hline Appropriate amount of physical activity $(<12 \cdot 8)$ & & & 255 & 218 & $22.66 \%$ & 36 & $3.74 \%$ \\
\hline Mild overexercise $(12 \cdot 8-17 \cdot 1)$ & & & 240 & 155 & $16 \cdot 11 \%$ & 76 & $7.90 \%$ \\
\hline Moderate overexercise $(17 \cdot 1-22.5)$ & & & 252 & 135 & $14.03 \%$ & 113 & $11.75 \%$ \\
\hline \multirow[t]{2}{*}{ Severe overexercise $(>22.5)$} & & & 236 & 124 & $12.89 \%$ & 105 & $10.91 \%$ \\
\hline & $-7 \cdot 27$ & $<0.001$ & & $17 \cdot 19$ & 6.92 & $20 \cdot 72$ & 7.54 \\
\hline
\end{tabular}

${ }^{*}$ CNY: Chinese Yuan (currency unit). The average exchange rate between USD and the CNY in 2016 was 6.6423.

†Since 2016, China has started the merger of New Rural Cooperative Medical Insurance System and Urban Residents Basic Medical Insurance, collectively referred to as URRMI. Due to the availability of data and the convenience of interpretation, the two were combined in this study. In addition, since the reimbursement ratio of urban employees after retirement is significantly higher than that before retirement, the UEBMI can be divided into two groups (not retired $v$. retired) according to China's statutory retirement age (males retire at the age of 60 and females retire at the age of 50 ).

‡BMI was calculated by the actually measured height and actually measured weight, and was divided into six categories according to Guidelines for the prevention and control of overweight and obesity in adults in China.

$\S$ Classified by quartile.

\section{Interaction analysis of chronic disease risk factors}

As shown in Table 4, there were both multiplicative interactions $(P=0.003)$ and additive interactions between excessive exercise $(\mathrm{PAI}>17 \cdot 1)$ and tea drinking on the occurrence of chronic diseases. The risk factor variables were converted into dichotomous variables, and their product items were included in the logistic regression model. After adjusting the relevant variables, the results showed that residents with excessive exercise $(\mathrm{PAI}>17 \cdot 1)$ and tea drinking had a lower risk of chronic disease than residents with relatively low exercise (PAI $<17 \cdot 1)$ and no tea drinking (OR $=0.40,95 \% \mathrm{CI}: 0.22,0.72)$, and the risk of chronic disease when the two exist together was lower than the sum of the risk caused by the two factors alone (relative excess risk due to interaction $=-5 \cdot 97$, attributable proportion due to interaction $=-15 \cdot 06, \mathrm{~S}=-0 \cdot 11$ ), that is, there was negative interaction. There was no multiplicative interaction between age $>60$ and overeating (DBI_TS $>0$ ) on the occurrence of chronic disease, but there was additive interaction (relative excess risk due to interaction $=-2 \cdot 47$, attributable proportion due to interaction $=-4.00$, $\mathrm{S}=-0 \cdot 18)$. The risk of chronic disease in people with age $>60$ and overeating was lower than the sum of the risk caused by the two factors alone, that is, there was negative interaction. In addition, there was no additive or multiplicative interaction between the combination of other risk factors and the risk of chronic disease.

\section{Medical insurance and chronic diseases: an analysis of the mediating effects of diet quality}

Table 5 presents the results of the mediation effect analysis. Models 1, 3, 5 and 7 were the results of logistic regression, 
Table 3 Logistic regression analysis of chronic disease risk factors $(n 962)$

\begin{tabular}{|c|c|c|c|c|c|c|c|c|}
\hline Variable & $\beta$ & Std. & $\chi^{2}$ value & $P$ & OR & $95 \% \mathrm{Cl}$ & Adjusted* OR & $95 \% \mathrm{Cl}$ \\
\hline \multicolumn{9}{|l|}{ Age (years) } \\
\hline $18-30$ & & & & & $1 \cdot 0$ & & 1.0 & \\
\hline $31-45$ & 0.83 & 0.82 & 1.02 & 0.31 & $3 \cdot 13$ & $0.63,15.49$ & $2 \cdot 28$ & $0.46,11.35$ \\
\hline $46-60$ & 1.93 & 0.79 & 5.99 & 0.01 & 9.52 & $2.09,43.49$ & $6 \cdot 88$ & $1.47,32 \cdot 21$ \\
\hline $61-75$ & $2 \cdot 15$ & 0.80 & $7 \cdot 28$ & 0.01 & 11.89 & $2 \cdot 62,54.03$ & 8.54 & $1.80,40.56$ \\
\hline$>75$ & $2 \cdot 32$ & 0.83 & 7.92 & 0.01 & $15 \cdot 26$ & $3 \cdot 20,72 \cdot 85$ & $10 \cdot 21$ & $2.02,51.52$ \\
\hline \multicolumn{9}{|l|}{ Tea drinking } \\
\hline Never or hardly & & & & & 1.0 & & 1.0 & \\
\hline Only on special occasion & 0.56 & 0.32 & $3 \cdot 12$ & 0.08 & 1.84 & $1.00,3.39$ & 1.76 & $0.94,3.28$ \\
\hline Only for certain months & $1 \cdot 10$ & 0.69 & 2.55 & 0.11 & 3.20 & $0.87,11.80$ & 3.00 & $0.78,11.53$ \\
\hline Every month (less than once a week) & 0.34 & 0.58 & 0.35 & 0.56 & 1.40 & $0.46,4.27$ & 1.41 & $0.45,4.41$ \\
\hline Every week & 0.61 & 0.18 & 11.77 & 0.00 & 1.98 & $1.41,2.76$ & 1.84 & $1 \cdot 30,2 \cdot 61$ \\
\hline \multicolumn{9}{|l|}{ Diet quality (DBI_TS) } \\
\hline Dietary under intake $(<-14)$ & & & & & 1.0 & & 1.0 & \\
\hline Mild dietary under intake $(-14-0)$ & 0.42 & 0.23 & 3.45 & 0.06 & 1.54 & $0.99,2.38$ & 1.52 & $0.98,2.36$ \\
\hline Mild overeating (0-8) & 0.71 & 0.22 & $10 \cdot 16$ & 0.00 & $2 \cdot 17$ & $1.41,3.35$ & $2 \cdot 04$ & $1 \cdot 32,3 \cdot 16$ \\
\hline Overeating (> 8) & 0.56 & 0.23 & $6 \cdot 17$ & 0.01 & 1.77 & $1 \cdot 14,2 \cdot 76$ & 1.76 & $1 \cdot 13,2 \cdot 74$ \\
\hline \multicolumn{9}{|l|}{ Physical activity index } \\
\hline Appropriate amount of physical activity $(<12.8)$ & & & & & 1.0 & & & \\
\hline Mild overexercise $(12 \cdot 8-17 \cdot 1)$ & 0.85 & 0.24 & $12 \cdot 67$ & 0.00 & 2.46 & $1.55,3.91$ & $2 \cdot 34$ & $1.47,3.74$ \\
\hline Moderate overexercise $(17 \cdot 1-22.5)$ & 1.42 & 0.23 & $36 \cdot 64$ & 0.00 & 4.56 & $2 \cdot 91,7 \cdot 14$ & $4 \cdot 13$ & $2 \cdot 61,6 \cdot 53$ \\
\hline Severe overexercise (> 22.5) & 1.49 & 0.24 & 37.53 & 0.00 & 4.79 & $3.01,7.64$ & 4.42 & $2 \cdot 75,7 \cdot 11$ \\
\hline
\end{tabular}

*Adjustment variables include gender, education, marital status, occupation, medical insurance, In (monthly family income) and registered residence in Shanghai or not.

and Models 2, 4 and 6 were the results of linear ordinary least squares (OLS) regression (although the frequency of tea drinking is actually a classification variable, for the sake of simplicity of analysis, when the number of classification levels of the classification variable is greater than or equal to 5 , it can be regarded as a continuous variable and put into the OLS regression equation $\left.{ }^{(28)}\right)$. Taking the mediating effect of DBI_TS on medical insurance and chronic disease as an example, Model 2 showed $\beta_{1}=-2 \cdot 36$, SE $\left(\beta_{1}\right)=0.66$, and $Z_{\beta_{1}}=-3.58$. Model 3 showed $\phi_{2}=0.02$, sE $\left(\phi_{2}\right)=0.01$, and $Z_{\varphi_{2}}=2$. Finally, using the product distribution method of R mediation software package, $95 \% \mathrm{CI}, Z_{\beta_{1}} Z_{\varphi_{2}}$ was $(-0.097,-0.007)$, excluding 0 . Therefore, diet quality had a significant mediating effect on the relationship between medical insurance and chronic diseases. According to Baron and Kenny causal stepwise regression analysis ${ }^{(29)}, \gamma_{1}, \beta_{1}, \phi_{1}$ and $\phi_{2}$ were significant (all $P<0 \cdot 05$; Table 5). Further confirming that diet quality was an incomplete mediator of the relationship between medical insurance and chronic disease while medical insurance also influenced chronic illnesses from other pathways. As shown in Table 5, the 95\% CI of PAI and tea drinking did not contain 0 , and the corresponding $\gamma_{1}, \beta_{1}, \phi_{1}$ and $\phi_{2}$ were both significant. Therefore, PAI and tea drinking were also incomplete mediators of medical insurance for chronic diseases.

\section{Discussion}

In the 2011 World Economic Forum, it was again emphasised that the five chronic diseases (cardiovascular diseases, tumor, diabetes, respiratory diseases and mental diseases) would have a profound impact on the national medical and economic systems in the next 20 years ${ }^{(30)}$. Shanghai has been an aging city since 1999, and the disease spectrum of the residents has changed greatly; furthermore, the prevention and treatment of chronic diseases in the elderly is facing severe challenges ${ }^{(31)}$. In this study, the survey showed that $34.99 \%$ of the investigated residents in Yangpu District of Shanghai suffered from chronic diseases. This higher prevalence, compared to that at the national level, could be explained by the relatively complete community-level health service system in Shanghai, which makes it possible to diagnose chronic diseases of community residents more timeously. In addition, Shanghai, being the financial center of China, regular overtime work by the residents and higher work pressure, may have contributed to the high prevalence of chronic diseases, to some extent ${ }^{(32-34)}$.

To prevent and control chronic diseases effectively, nutrition, diet and exercise are the key factors. Imbalanced diet, including overeating, is a major contributor to chronic diseases. Compared with normal dietary intakes, people who eat excessively are at higher risks of chronic diseases, which is consistent with the findings of previous studies ${ }^{(35-37)}$. With changes in diet structure, the consumption of refined cereals increases, and long-term consumption causes insufficient intake of vitamins, minerals, dietary fibre, etc ${ }^{(38)}$. Excessive intake of high-sodium food also increases the risk of chronic diseases ${ }^{(39)}$. Consistent with the conclusion of previous studies, the older the person, the higher the risk of chronic diseases ${ }^{(40)}$. However, in this study, it was found that there was negative additive interaction between age $>60$ and overeating 
Lifestyle and dietary factors on chronic diseases

Table 4 Interaction analysis of chronic disease risk factors ( $n$ 962)

\begin{tabular}{|c|c|c|c|c|c|c|}
\hline Variable 1 & Variable 2 & $\begin{array}{c}\text { Having } \\
\text { chronic dis- } \\
\text { ease (yes/no) }\end{array}$ & OR & $95 \% \mathrm{Cl}$ & $\begin{array}{c}\text { Adjusted* OR } \\
(\mathrm{aOR})\end{array}$ & $95 \% \mathrm{Cl}$ \\
\hline Age $(>60)$ & $\begin{array}{l}\text { Overexercise } \\
\quad \text { (Physical Activity } \\
\text { Index, PAl > 17.1) }\end{array}$ & & & & & \\
\hline No & No & $36 / 144$ & & & & \\
\hline No & Yes & $84 / 144$ & 2.33 & $1.48,3.67$ & $2 \cdot 31$ & $1.46,3 \cdot 70$ \\
\hline Yes & No & $76 / 229$ & 1.33 & $0.85,2.08$ & 1.29 & $0.80,2.04$ \\
\hline Yes & Yes & $134 / 115$ & 1.51 & $0.84,2.69$ & 1.37 & $0.76,2.47$ \\
\hline \multirow[t]{3}{*}{ Additive interaction } & & & $\begin{array}{l}\text { Relative excess risk } \\
\text { due to interaction } \\
\text { (RERI) }=-1.23\end{array}$ & $-2 \cdot 91,0.45$ & & \\
\hline & & & $\begin{array}{l}\text { Attributable proportion } \\
\text { due to interaction } \\
(\mathrm{AP})=-0.39\end{array}$ & $-1 \cdot 99,0 \cdot 19$ & & \\
\hline & & & $S=0.23$ & $0.03,1.99$ & & \\
\hline $\begin{array}{c}\text { Multiplicative } \\
\text { interaction }\end{array}$ & & & $\operatorname{aOR}(95 \% \mathrm{Cl})=1.37$ & $0 \cdot 76,2 \cdot 47$ & $P=0.30$ & \\
\hline Age $(>60)$ & $\begin{array}{l}\text { Overeating } \\
\quad(\text { DBI_TS > 0) }\end{array}$ & & & & & \\
\hline No & No & $45 / 162$ & & & & \\
\hline No & Yes & $75 / 126$ & $2 \cdot 14$ & $1 \cdot 39,3 \cdot 32$ & $2 \cdot 20$ & $1.41,3.44$ \\
\hline Yes & No & $94 / 188$ & 1.80 & $1 \cdot 19,2 \cdot 72$ & 1.88 & $1.22,2.92$ \\
\hline Yes & Yes & $116 / 156$ & 0.69 & $0.40,1 \cdot 21$ & 0.62 & $0.35,1.09$ \\
\hline Additive interaction & & & $\begin{array}{l}\text { RERI }=-2.47 \\
A P=-4.00 \\
S=-0.18\end{array}$ & $\begin{array}{l}-4.85,-0.08 \\
-6.58,-1.42\end{array}$ & & \\
\hline $\begin{array}{c}\text { Multiplicative } \\
\text { interaction }\end{array}$ & & & $\operatorname{aOR}(95 \% \mathrm{Cl})=0.62$ & $0.35,1.09$ & $P=0.98$ & \\
\hline Age $(>60)$ & Tea drinking & & & & & \\
\hline No & No & $61 / 205$ & & & & \\
\hline No & Yes & $59 / 83$ & & $2.391 .54,3.71$ & $2 \cdot 35$ & $1.49,3.72$ \\
\hline Yes & No & $115 / 263$ & 1.47 & $1 \cdot 03,2 \cdot 11$ & 1.41 & $0.95,2.07$ \\
\hline Yes & Yes & $95 / 81$ & $1 \cdot 12$ & $0.63,1.99$ & 1.04 & $0.57,1.87$ \\
\hline Additive interaction & & & $\mathrm{RERI}=-1 \cdot 72$ & $-3 \cdot 68,0 \cdot 23$ & & \\
\hline & & & $\begin{array}{l}A P=-1.67 \\
S=0.02\end{array}$ & $\begin{array}{l}-3.14,-0.19 \\
0.00,42919508.91\end{array}$ & & \\
\hline $\begin{array}{c}\text { Multiplicative } \\
\text { interaction }\end{array}$ & & & $\operatorname{aOR}(95 \% \mathrm{Cl})=1.04$ & $0.57,1.87$ & $P=0.91$ & \\
\hline $\begin{array}{l}\text { Overexercise } \\
\qquad(\mathrm{PAI}>17 \cdot 1)\end{array}$ & $\begin{array}{l}\text { Overeating } \\
\quad(\text { DBI_TS > 0) }\end{array}$ & & & & & \\
\hline No & No & $48 / 218$ & 1.0 & & 1.0 & \\
\hline No & Yes & $64 / 155$ & 1.88 & $1 \cdot 22,2 \cdot 88$ & 1.78 & $1.15,2.74$ \\
\hline Yes & No & $91 / 132$ & $3 \cdot 13$ & $2 \cdot 08,4.72$ & 3.03 & $1.98,4.63$ \\
\hline Yes & Yes & $127 / 127$ & 0.77 & $0.44,1.36$ & 0.82 & $0.46,1.45$ \\
\hline Additive interaction & & & $\begin{array}{l}\text { RERI }=-2.98 \\
A P=-3.64 \\
S=-0.07\end{array}$ & $\begin{array}{l}-6 \cdot 01,0.04 \\
-6 \cdot 30,-0.99\end{array}$ & & \\
\hline $\begin{array}{c}\text { Multiplicative } \\
\text { interaction }\end{array}$ & & & $\operatorname{aOR}(95 \% \mathrm{Cl})=0.82$ & $0.46,1.45$ & $P=0.49$ & \\
\hline $\begin{array}{l}\text { Overexercise } \\
\qquad(\text { PAI }>17 \cdot 1)\end{array}$ & Tea drinking & & & & & \\
\hline No & No & $62 / 308$ & 1.0 & & 1.0 & \\
\hline No & Yes & $50 / 65$ & 3.82 & $2 \cdot 42,6.05$ & 3.78 & $2.35,6.09$ \\
\hline Yes & No & $114 / 160$ & 3.54 & $2.46,5.09$ & 3.59 & $2 \cdot 46,5 \cdot 23$ \\
\hline Yes & Yes & $104 / 99$ & 0.38 & $0.21,0.69$ & 0.40 & $0.22,0.72$ \\
\hline Additive interaction & & & $\begin{array}{l}\text { RERI }=-5.97 \\
A P=-15 \cdot 06 \\
S=-0.11\end{array}$ & $\begin{array}{l}-11 \cdot 15,-0.80 \\
-23.26,-6.87\end{array}$ & & \\
\hline $\begin{array}{c}\text { Multiplicative } \\
\text { interaction }\end{array}$ & & & $\operatorname{aOR}(95 \% \mathrm{Cl})=0.40$ & $0.22,0.72$ & $P=0.003$ & \\
\hline Tea drinking & $\begin{array}{l}\text { Overeating } \\
\quad(\text { DBI_TS }>0)\end{array}$ & & & & & \\
\hline No & No & $77 / 269$ & 1.0 & & 1.0 & \\
\hline No & Yes & 99/199 & 1.74 & $1 \cdot 23,2 \cdot 47$ & 1.68 & $1.17,2 \cdot 39$ \\
\hline Yes & No & $62 / 81$ & $2 \cdot 67$ & $1.76,4.06$ & 2.59 & $1.68,4.00$ \\
\hline Yes & Yes & $92 / 83$ & 0.83 & $0.47,1.47$ & 0.84 & $0.47,1.50$ \\
\hline
\end{tabular}


Table 4 Continued

\begin{tabular}{|c|c|c|c|c|c|c|}
\hline Variable 1 & Variable 2 & $\begin{array}{c}\text { Having } \\
\text { chronic dis- } \\
\text { ease (yes/no) }\end{array}$ & OR & $95 \% \mathrm{Cl}$ & $\begin{array}{c}\text { Adjusted* OR } \\
(\mathrm{aOR})\end{array}$ & $95 \% \mathrm{Cl}$ \\
\hline Additive interaction & & & $\begin{array}{l}\text { RERI }=-2.43 \\
A P=-2.90 \\
S=-0.07\end{array}$ & $\begin{array}{l}-4 \cdot 97,0 \cdot 11 \\
-5 \cdot 09,-0.72\end{array}$ & & \\
\hline $\begin{array}{c}\text { Multiplicative } \\
\text { interaction }\end{array}$ & & & $\operatorname{aOR}(95 \% \mathrm{Cl})=0.84$ & $0.47,1.50$ & $P=0.55$ & \\
\hline
\end{tabular}

*Adjustment variables include gender, education, marital status, occupation, medical insurance, monthly family income and registered residence in Shanghai or not.

(DBI_TS $>0$ ) on chronic disease, which may be due to deviation in the measurement of diet quality by DBI_TS. DBI_16 is generally suitable for the dietary evaluation of adults. The elderly (age $>60$ ) have very different nutritional requirements from normal adults due to their special physiological characteristics ${ }^{(16)}$. In addition, continuous variable DBI_TS may have a U-shaped relationship with the risk of chronic disease, which needs to be further explored in future studies. However, healthy food habits are always protective factors for chronic diseases. Eating reasonably is the basis of human health, and nutrient deficiency or excess may occur with long-term insufficient or excessive nutrient consumption ${ }^{(41-44)}$. Moreover, dietary nutrition has a long-term impact on health, and unreasonable dietary structure and pattern are facilitating factors for the occurrence of chronic diseases ${ }^{(45-47)}$.

Considering other aspects of diet habits, the high frequency of tea drinking increases the risks of chronic diseases. A prospective cohort study conducted in Zhejiang Province showed that moderate tea consumption could reduce the risk of stroke ${ }^{(48)}$. However, an epidemiological investigation on the incidence of diabetes in Changsha City suggested that patients with gout or hyperuricaemia should not drink tea ${ }^{(49)}$. Although the caffeine content of different teas varies depending on the production place, type and processing technic, Chinese consumers preferred more traditional tea varieties containing caffeine, such as green tea, black tea and oolong tea ${ }^{(50)}$.Long-term excessive drinking of tea results in the over accumulation of caffeine in the body. This impairs the nervous and digestive system functions, increases the burden on the kidneys, and results in nervousness, fatigue and discomfort, headache and other symptoms in people ${ }^{(51)}$.

With physical activity, excessive exercise also increases the risk of chronic diseases, as it can lead to cardiovascular events, musculoskeletal injuries, upper respiratory infections, gastrointestinal symptoms or sudden death due to multi-organ system failure ${ }^{(52,53)}$. However, there were negative additive and multiplicative interactions between PAI greater than $17 \cdot 1$ and tea drinking on the occurrence of chronic diseases. May be associated with the increase of physical activity intensity, there will be internal organs, muscles and nervous fatigue, the tea polyphenols can promote metabolism, accelerate liver detoxification and the caffeine, tea polysaccharide, amino acid and other nutrients can strengthen physique and eliminate fatigue $^{(54,55)}$. Thus excessive physical activity combined with tea drinking reduced the risk of chronic diseases. It is likely that there is a U-shaped relationship between physical activity and chronic disease risk, which needs to be further analysed in future studies.

In addition, higher reimbursement level of medical insurance reduces the risk of chronic diseases, which is supported by a natural experiment, which showed that switching from Urban Residents Basic Medical Insurance to Urban Employees Basic Medical Insurance significantly improved health ${ }^{(56)}$. In fact, in the current social basic medical insurance system in China, the urban employee compensation rate and maximum compensation amount are higher than those for urban and rural residents. Therefore, it is more likely for people with Urban Employees Basic Medical Insurance to utilise medical services due to the higher reimbursement value, which indirectly affects the residents' health ${ }^{(57)}$. The mediating effect analysis on the impact of medical insurance on chronic disease showed that residents with higher reimbursement level of medical insurance had lower DBI_TS and PAI and less frequent drinking of tea. This is inconsistent with previous research conclusions, which believe that while medical insurance increases the accessibility of medical services, it may also lead the insured to reduce their investment in preventing disease risk before getting ill, thus leading to 'ex-ante moral hazard'(58). In this study, residents who participated in high-reimbursement health insurance were likely to be more risk averse and therefore focused more on eating a balanced diet and exercising reasonably, as well as limiting caffeine intake in tea, thereby reducing the probability of chronic disease, which further proved the robustness of the conclusion that participation in high-reimbursement health insurance can reduce the risk of chronic disease.

There are several limitations to this study. First, it was conducted in one district of Shanghai, due to the possible sampling bias, the respondents age showed a large proportion of aging. Therefore, the application of the findings to other areas needs to be done with caution. Second, we were unable to assess for the presence of undiagnosed 
chronic diseases in the population, and some answers were recalled and reported by participants, which could cause recall bias and response biases. Third, the study design was limited to some extent by the availability of data, and the cross-sectional data made it impossible to demonstrate causality between lifestyle factors and chronic disease. It is also a question need to be further explored. In addition, if data on alcohol consumption and severity of chronic diseases are available, further studies can be conducted in the future.

In conclusion, the proportion of residents suffering from chronic diseases in Yangpu District was relatively high. The age, diet habit, tea drinking habit and the amount of exercise were main risk factors of chronic diseases. Health insurance improved residents' access to medical services. But contrary to the conclusions of previous studies, this study proved that there was no ex-ante moral hazard of medical insurance among the surveyed residents. To facilitate the prevention and control of chronic diseases, the community residents should be encouraged to develop balanced eating habits and healthy exercise behaviours. In addition, the government should focus on improving the nutritional environment of old people, strengthening access to health education, coordinate different types of medical insurance to promote access to health services by the residents.

\section{Acknowledgments}

Acknowledgments: Thanks for the questionnaire and data support provided by Shanghai Yangpu District CDC. Financial support: The design of this study involving some previous investigation was supported by the Natural Science Foundation of China (71603182, 71774116, 72104140 and 82101870). Data extraction was financially funded by the National Key R\&D Program of China (2018YFC2000700). The analysis and interpretation of the data guided by the statisticians were funded by the Shanghai Pujiang Program (2019PJC072, 21PJC083 and 2020PJC081), the Shanghai Health System Outstanding Talents Program (2018YQ52) and the Shanghai Public Health Outstanding Young Personnel Training Program (GWV-10-2-XD07). The writing and revision, including the language improvement, were sponsored by Zhejiang Provincial Natural Science Foundation of China (LQ21H100001), Soft Science Project of Shanghai Science and Technology Innovation Action Plan (21692191300) and Connotation Foundation of Shanghai Jiao Tong University School of Medicine (17ZYGW12). Conflict of interest: There are no conflicts of interest. Authorship: Y.Y. interpreted the data and drafted the manuscript. H.J. and P.Z. analysed and interpreted the data. M.C. has made substantial contributions to conception and design. X.L. revised the manuscript. Z.C. and X.G. acquired of data. L.Z., Y.Lv., J.H. and N.C. analysed and interpreted the data. 
W.Y., Z.W. and J.S. involved in analysis and interpretation of data, revising the manuscript and given final approval of the version to be published. Ethics of human subject participation: This study was approved by the ethics committees of Tongji University (ref: LL-2016-ZRKX-017). Official permission was obtained from selected hospitals and health centres. Confidentiality was kept and informed verbal consent was obtained from each study participants after explaining the purpose of the study. Verbal informed consent was approved by the Tongji University Research and Ethics Committee. This research was carried out in accordance with the principles of the Declaration of Helsinki.

\section{References}

1. Liu J \& Sun J (2011) A survey of chronic diseases among Community residents in Jinan city in 2009. J Community $\operatorname{Med}$ 9, 49-50.

2. World Health Organization (WHO) (2017) World Health Statistics 2017: Monitoring Health for the SDGs. http://www. indiaenvironmentportal.org.in/content/442747/world-healthstatistics-2017-monitoring-health-for-the-sdgs/ (accessed October 2021).

3. World Health Organization (WHO) (2013) Noncommunicable Diseases Introduction. https://www.who. int/health-topics/noncommunicable-diseases\#tab=tab_1 (accessed December 2020).

4. World Health Organization (WHO) (2020) World Health Statistics 2020. https://www.who.int/gho/publications/world_ health_statistics/2020/en/ (accessed December 2020).

5. World Health Organization (WHO) (2005) Preventing Chronic Disease: A Vital Investment. https://www.who.int/chp/chronic_ disease_report/order_form.pdf (accessed October 2021).

6. Lu SR, Su J, Zhang FY et al. (2014) Prevalence of chronic diseases and related risk factors among residents in Jiangsu province, China. Chin J Public Health 30, 8-12.

7. Sun WW \& Gu Q (2011) The analysis on the risk factors of chronic disease among the residents in four suburban districts of Tianjin. Chin J Prev Contr Chron Non-Communic Dis 19, 148-149.

8. Bi PM, Wang FY, Ma RJ et al. (2010) Study on chronic diseases of the urban and rural residents in a South Anhui Mountain area and the analysis of their influencing factors. Anbui Med J 31, 119-122.

9. Kinra S, Bowen LJ, Lyngdoh $T$ et al. (2010) Sociodemographic patterning of non-communicable. Disease risk factors in rural India: a cross sectional study. BMJ341, c 4974.

10. Wu F, Guo Y, Chatterji S et al. (2015) Common risk factors for chronic non-communicable diseases among older adults in China, Ghana, Mexico, India, Russia and South Africa: the study on global ageing and adult health (SAGE) wave 1 . BMC Public Health 15, 88.

11. Sun X, Wang P, Liu L et al. (2014) Analysis on the status and influencing factors of chronic diseases among rural residents in Ningxia Hui Autonomous Region. Chinese J Public Health 12, 1516-1520.

12. Li WQ, Zhang QQ, Jiang LL et al. (2014) Analysis of chronic disease prevalence and influencing factors among residents in Chaoyang District of Changchun. Chin J Public Health 6, 735-739.

13. Luo Y, Zheng ZQ \& Lu RY (2010) Study on present situation and countermeasure of community chronic diseases prevention in Fuzhou. Med Soc 23, 7-9.
14. Li XX, Luo ZB \& Zhang SZ (2008) Analysis of the risk factors of chronic diseases among monitored population in Binyang county of Guangxi. Mod Prev Med 35, 4232-4234.

15. Ren S, Li X, Cui YF et al. (2020) The dietary quality of adult residents in Liaoning province was evaluated by using The Chinese dietary balance index. Chin J Health Educ 36, 880-884.

16. He NY, Zhai FY \& Ge KY (2005) Establish China's dietary balance index. J Hygiene Res 34, 208-211.

17. He YN, Fang YH \& Xia J (2018) Revision of China's dietary balance index: DBI-16. Acta Nutrimenta Sinica 40, 526-530.

18. Anonymity (2007) Measure your activity level. Chin J Orthopaedic Trauma 06, 605.

19. Andersson T, Alfredsson L, Kullberg H et al. (2005) Calculating measures of biological interaction. Eur $J$ Epidemiol 20, 575-579.

20. Westreich D \& Greenland S (2013) The table 2 fallacy: presenting and interpreting confounder and modifier coefficients. Am J Epidemiol 177, 292-298.

21. Liu YH, Luo F, Zhang Y et al. (2013) The dependent variable is the mediating effect analysis of the rank variable. Acta Psychologica Sin 45, 1431-1442.

22. Wen ZL \& Ye BJ (2014) Mediating effect analysis: methods and model development. Adv Psychol Sci 22, 731-745.

23. Perignon D (1981) Logistic regression diagnostics. Ann Statistics 9, 705-724.

24. MacKinnon DP (2008) Introduction to Statistical Mediation Analysis. Mahwah, NJ: Erlbaum.

25. MacKinnon DP \& Dwyer JH (1993) Estimating mediated effects in prevention studies. Evaluation Rev 17, 144-158.

26. MacKinnon DP, Lockwood CM, Brown CH et al. (2007) The intermediate endpoint effect in logistic and probit regression. Clin Trials 4, 499-513.

27. Susuman AS, Hamisi HF, Lougue S et al. (2015) An assessment of the age reporting in tanzania population census 2012. J Soc Sci Res 08, 1553-1563.

28. Fang J, Wen ZL \& Zhang MQ (2017) Mediating effect analysis of category variables. J Psychol Sci $\mathbf{4 0}, 471-477$.

29. Baron RM \& Kenny DA (1986) The moderator-mediator variable distinction in social psychological research: conceptual, strategic, and statistical considerations. J Pers Social Psychol 51, 1173-1182.

30. Hainan Daily (2011) The World Economic Forum released the Report Top 5 Chronic Diseases in the next 20 years. http://hnrb.hinews.cn/html/2011-09/20/content_400100.htm (accessed October 2021).

31. Zhao YF, Wang R, Yan XY et al. (2010) Study on the relationship between chronic diseases and health related quality of life among citizens in Shanghai. Chin J Health Stat 27, 28-30.

32. Müller G, Anita T \& Marti WA (2018) The impact of long working hours on the health of German employees. Ger J Hum Resour Manage Z Für Personalforschung 32, 239700221878602.

33. Li B, Li Z \& Wan Q (2019) Effects of work practice environment, work engagement and work pressure on turnover intention among community health nurses: mediated moderation model. J Adv Nurs 75, 3485-3494.

34. Sheng W, Zheng X, Fei L et al. (2016) Work-recreation balance, health-promoting lifestyles and suboptimal health status in southern China: a cross-sectional study. Int J Environ Res Public Health 3, 339.

35. Patel DN, Nossel C, Alexander E et al. (2013) Innovative business approaches for incenting health promotion in Sub-Saharan Africa: progress and persisting challenges. Prog Cardiovasc Dis 56, 356-362.

36. Martinez-Ferran M, Guía-Galipienso FDL, Sanchis-Gomar F et al. (2020) Metabolic impacts of confinement during the 
covid-19 pandemic due to modified diet and physical activity habits. Nutrients 12, 1549.

37. Mills JG, Thomas SJ, Larkin TA et al. (2020) Overeating and food addiction in major depressive disorder: links to peripheral dopamine. Appetite 148, 104586.

38. Su YP, Yang K, Liu XD et al. (2021) Study on dietary behavior and risk of chronic disease among adult population in Beijing. Prev Med 33, 111-116.

39. Tian T, Ma L \& Jia H (2019) Research progress on the relationship between dietary pattern and high blood pressure, type 2 glycourine disease and hyperuricemia.J Southwest Med Univ 42, 594-598.

40. Xu ZG (2005) The correlation between the prevalence of some chronic diseases and age. Chin J Clin Healthcare 5 , 433-435.

41. Ma YX, Sha YH, Tan X et al. (2020) Investigation and analysis on the influencing factors of chronic diseases among the elderly in poor areas of West Hunan. J Community Med 22, 1501-1504

42. Zhou YL, Ran JC, Deng YL et al. (2019) Analysis on the status quo and influencing factors of chronic diseases among residents in Hami City. Mod Prev Med 46, 1096-1099.

43. Li SR, Zhu ZH, Qi Q et al. (2020) Analysis of chronic disease and its influencing factors in Zhenba County, Shaanxi Province. J Xi'an Jiaotong Univ 41, 460-467.

44. You J, Yuan YQ, Li SG et al. (2020) A study on the correlation between dietary pattern and obesity of adult residents in Shanghai. Shanghai J Prev Med 2020, 294-299.

45. Chia AR, deSeymour JV, Colega M et al. (2016) A vegetable, fruit, and white rice dietary pattern during pregnancy is associated with a lower risk of preterm birth and larger birth size in a multiethnic Asian cohort: the Growing Up in Singapore Towards healthy Outcomes (GUSTO) cohort study. Am J Clin Nutr 104, 1416-1423.

46. Yin ZX \& Zhao WH (2017) Dietary patterns are key to nutrition and health. Chin J Health Manage 11, 3-6.

47. Monneuse MO, Bellisle F \& Koppert G (1997) Eating habits, food and health related attitudes and beliefs reported by French students. Eur J Clin Nutr 1, 46-53.
48. Wang H, Du HD, Hu RY et al. (2018) A prospective study on the association between tea drinking and stroke in adults in Zhejiang Province. Chin J Epidemiol 39, 1200-1205.

49. Tang DH, Xia B \& Wu HQ (1996) The influence of drinking tea on the health of the elderly in urban areas. China Tea $\mathbf{5}$, 29-30.

50. iiMedia Research (2021) Analysis of Chinese Consumers' Tea Types Related Portraits and Consuming Behavior in 2021. https://zhuanlan.zhihu.com/p/348981121 (accessed December 2020).

51. Gao G \& Tao R (2001) Study on hygiene of harmful elements As, $\mathrm{Ba}, \mathrm{Cd}$ and $\mathrm{Pb}$ in tea. Chin J Food Hyg 13, 12-14.

52. Liu XJ, Wang J \& Zeng SQ (2011) Analysis on the current situation and causes of fitness risk events. J Beijing Sport Univ 10, 51-54.

53. Wang H, Su H \& Xie MH (2010) Theory and Method of Health Risk Assessment of Excessive Exercise. Abstract of Papers of the Second National Fitness Science Congress. https://kns. cnki.net $/ \mathrm{kcms} /$ detail/detail.aspx?dbcode $=$ CPFD\&dbname $=$ CPFD0914\&filename $=$ ZGTK201005002216\&uniplatform $=$ NZKPT\&v=7bbILfiEOfwgOX5zrdwWS_fIrdt53Tm5Nl3HBXKG Vvjv1xPDc-tqCbb1VYhHuj-A3E-o6_BusxQ\%3d (accessed November 2021).

54. $\mathrm{Li} \mathrm{T}$ (2018) The application of tea polyphenols in the promotion of human physique health care. Tea Fujian $\mathbf{4 0}, 33$.

55. Zhou XD (2016) Studies on the physiological effects of theanine and its relationship with exercise. Tea Fujian 38, 26-27.

56. Zhou J, Deng QL \& Liu HY (2020) How the basic medical insurance affect health equity for the elderly: research on structural equation model. Financial Econ Res 35, 147-160.

57. Ma C, Gu H \& Sun XH (2015) Does higher grade of medical insurance lead to better health: evidence from nature experiment of urban - rural integrated medical insurance system. J Public Manage 02, 157-158.

58. Peng XB \& Qin XZ (2015) Does health insurance cause ex-ante moral hazard? Theoretical analysis and empirical evidence. China Econ $Q$ 14, 159-184. 